\title{
Diel movements of juvenile smalltooth sawfish: implications for defining the size of a nursery hotspot
}

\author{
Cecily A. Huston ${ }^{1,2}$, Philip W. Stevens ${ }^{3}$, Rebecca M. Blaxton ${ }^{1}$, S. Gregory Tolley ${ }^{2}$, \\ Rachel M. Scharer ${ }^{1}$, Brett M. Tornwall ${ }^{4}$, Gregg R. Poulakis ${ }^{1,2, *}$ \\ ${ }^{1}$ Fish and Wildlife Research Institute, Florida Fish and Wildlife Conservation Commission, \\ Charlotte Harbor Field Laboratory, Port Charlotte, FL 33954, USA \\ ${ }^{2}$ Department of Marine and Ecological Sciences, Florida Gulf Coast University, Fort Myers, FL 33965, USA \\ ${ }^{3}$ Fish and Wildlife Research Institute, Florida Fish and Wildlife Conservation Commission, St. Petersburg, FL 33701, USA \\ ${ }^{4}$ Center for Biostatistics and Modeling, Fish and Wildlife Research Institute, \\ Florida Fish and Wildlife Conservation Commission, Gainesville, FL 32601, USA
}

\begin{abstract}
Habitat use and movements of juvenile ( $<3 \mathrm{yr}$ old) Critically Endangered smalltooth sawfish Pristis pectinata were studied in the Peace River nursery in southwest Florida to estimate the size of a known nursery hotspot (high-use area). A total of 23 smalltooth sawfish were tagged during the peak recruitment period of April and May 2014 and tracked until the end of September 2014 using passive acoustic monitoring. Active tracking was also used to estimate positions of individuals relative to the shoreline and major habitat types. During the day, sawfish $<1500 \mathrm{~mm}$ stretch total length $\left(\mathrm{STL}_{;} \mathrm{n}=11\right)$, representing <1-yr-old fish, and those between 1504 and $1881 \mathrm{~mm}$ STL $(\mathrm{n}=12)$, representing $\geq 1$-yr-old fish (1 to $3 \mathrm{yr}$ old), remained along the northern shoreline of the river, in a protected cove. The younger age class remained closer $(<25 \mathrm{~m})$ to redmangrove-dominated shorelines than did the older age class. At night, both age classes moved further away from the shoreline and away from the protected cove; the older individuals made the longest excursions $(\sim 5 \mathrm{~km})$, toward the southern shoreline of the river. The discovery of these regular diel movements led to the expansion of the boundaries of the single recognized nursery hotspot in the Peace River, which was previously defined solely on daytime catch data. If another layer of protection is needed in the hotspots relative to other areas within the sawfish critical habitat, then defining the boundaries of the hotspots has implications with respect to management plans, federal permitting activities, and restoration opportunities.
\end{abstract}

KEY WORDS: Pristis pectinata $\cdot$ Acoustic tracking and monitoring $\cdot$ Habitat use $\cdot$ Management

\section{INTRODUCTION}

Of the chondrichthyan fishes, sawfishes (Pristidae) are the most threatened (Dulvy et al. 2014), which elevates the urgency for reducing threats to their populations and delineating critical habitats. Globally, 3 of the 5 sawfish species are listed as Critically Endangered on the International Union for Conservation of Nature Red List of Threatened Species

${ }^{*}$ Corresponding author: gregg.poulakis@myfwc.com
(Carlson et al. 2013, Kyne et al. 2013, Simpfendorfer 2013). All 5 species face the risk of extinction due to declines in their ranges and spatial distributions (Dulvy et al. 2016). Historically, the Critically Endangered smalltooth sawfish Pristis pectinata was found in the USA along the coast from Texas to the midAtlantic, but because of largely unintentional overfishing, the population has declined, and the range has been reduced to primarily southwestern Florida

(C) The authors 2017. Open Access under Creative Commons by Attribution Licence. Use, distribution and reproduction are unrestricted. Authors and original publication must be credited. 
(NMFS 2009). In 2003, the smalltooth sawfish became the first elasmobranch to be listed as endangered under the US Endangered Species Act, but has been formally protected in Florida waters since 1992 (FWC 1999, NMFS 2003). In Florida, there are 2 designated critical habitat areas for juvenile smalltooth sawfish - the Charlotte Harbor Estuary Unit and the Ten Thousand Islands/Everglades Unit (NMFS 2009, Norton et al. 2012) - and both areas continue to serve as functional nurseries (Poulakis et al. 2011, Hollensead et al. 2016).

Within these critical habitats, there is growing evidence to suggest that there are small regions of high use, termed hotspots, in the nurseries that are crucial refuges during the species' early life history (Poulakis et al. 2011, 2013, 2016, Hollensead et al. 2016). In the Charlotte Harbor Estuary Unit, juvenile smalltooth sawfish are found primarily in 2 nurseries associated with the Peace and Caloosahatchee rivers (Poulakis et al. 2011, Scharer et al. 2017, this Theme Section). These rivers are among the largest (in terms of freshwater flow) in the current range of smalltooth sawfish and have similar environmental conditions; yet multiple lines of evidence demonstrate that there are multiple nursery hotspots in the broad ( 25 river $\mathrm{km}$; $\mathrm{rkm})$, lower region of the Caloosahatchee River and only 1 hotspot in the relatively short ( $\sim 10 \mathrm{rkm})$, lower region of the Peace River (Poulakis et al. 2011, 2013, 2016, Scharer et al. 2017). Differences in geomorphology and water management between the rivers are believed to contribute to this variation in habitat use between nurseries (Scharer et al. 2017). An understanding of how the nursery hotspots are being used by juvenile smalltooth sawfish is needed to define their approximate boundaries and identify what habitats are being used within them (Poulakis et al. 2016). If another layer of protection is needed in the hotspots relative to other areas within the sawfish nurseries and critical habitat areas, then defining the boundaries of the hotspots has implications with respect to management, federal permitting activities, and restoration opportunities.

A major factor that may influence the size of a nursery hotspot is diel behavior, that is, if habitat use varies substantially between day and night. Most of the initial research examining the use of juvenile smalltooth sawfish nursery hotspots within the Charlotte Harbor Estuary Unit was either based on daytime sampling or, in the case of acoustic monitoring, was not designed to test for diel differences in movement (Poulakis et al. 2011, Simpfendorfer et al. 2011). More recent studies, however, have attempted to deploy acoustic receivers in a way to detect any diel differences in movement (Poulakis et al. 2013, 2016). Activity in the main stem of the Caloosahatchee River was found to be greater at night than during the day, suggesting the possibility of diel differences, although the authors could not rule out the possibility that differences in noise regimes between day and night could partially explain the findings (Poulakis et al. 2013). In studies investigating site fidelity and habitat use of smalltooth sawfish within nursery hotspots in the Caloosahatchee River and Ten Thousand Islands, movement data from a few individuals ( $\mathrm{n}=4$ to 7 ) documented regular movements from a canal system to the main stem of the river at night and higher rates of movement at night (Hollensead et al. 2016, Poulakis et al. 2016). Although evidence is mounting that juvenile sawfish exhibit diel differences in movement, similar to other elasmobranchs (Holland et al. 1993, Matern et al. 2000, Cartamil et al. 2003), a definitive study with a larger sample size ( $\mathrm{n}>20$ individuals) is needed. More importantly, fine-scale information that allows scientists and managers to define the boundaries of nursery hotspots, taking into consideration the space used by sawfish over $24 \mathrm{~h}$ periods, is needed for more refined spatial management.

The objective of this study was to test the hypothesis that juvenile smalltooth sawfish exhibit diel movement patterns and to determine if the differences in space used between day and night are substantial enough to influence spatial management of the species. To test this hypothesis, an array of passive acoustic monitoring stations, deployed in a manner that could detect diel changes in movement, was used to estimate the size of a known nursery hotspot in the Peace River. In addition, a mobile hydrophone survey was used to confirm the positions of sawfish during the day and night, and to determine fine-scale habitat use within the hotspot. These data are crucial for aiding the conservation of this Critically Endangered species within its federally designated critical habitat.

\section{MATERIALS AND METHODS}

Sampling for smalltooth sawfish Pristis pectinata was conducted in northern Charlotte Harbor, which includes the lower Peace and Myakka rivers (Fig. 1). In southwest Florida, December to May is considered the dry season and June to November is considered the wet season. Salinity in the Charlotte Harbor estuarine system ranges from 5 to 37.9, depending on season (Poulakis et al. 2003). The northern shoreline 


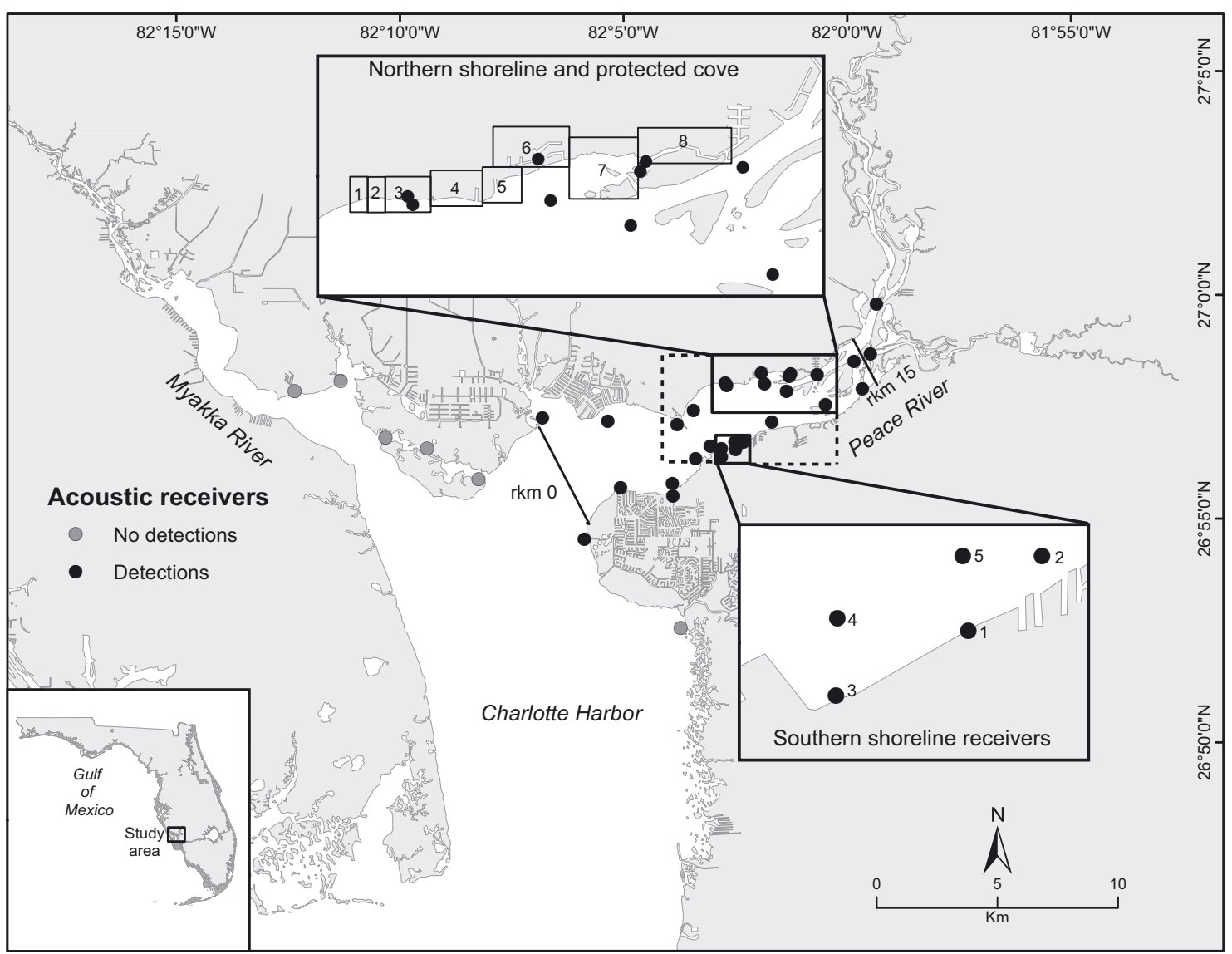

Fig. 1. Northern Charlotte Harbor, including the Myakka and Peace rivers. Acoustic receivers that recorded detections from smalltooth sawfish Pristis pectinata during the study (May to September 2014; $\bullet$ ) and acoustic receivers that did not record detections $(\bullet)$ are shown. Enlargement of the northern shoreline shows the sites used for daytime active acoustic tracking within the previously defined nursery hotspot (Poulakis et al. 2011). Site 7 is the 'protected cove' referred to in the text. Enlargement of the southern shoreline shows the location of 5 acoustic receivers along that portion of the river. Numbers on the southern shoreline receivers correspond with the monitoring histories in Fig. 2. Dashed box represents the revised nursery hotspot boundary based on diel data (see Figs. 4 \& 5). River kilometer ( $\mathrm{rkm}$ ) refers to the distance from the river mouth (at rkm 0 )

of the Peace River is a known nursery hotspot for juvenile smalltooth sawfish; that is, research captures and reports of sightings by the public are far more numerous than elsewhere in the upper estuary (Poulakis et al. 2011). Shorelines in the lower portion of the Peace River are shallow (0.1 to $1.2 \mathrm{~m})$. The northern shoreline has a variety of habitats including overhanging red mangroves Rhizophora mangle, seawall, rip rap, beach, Spartina spp. and Juncus spp. The southern shoreline is dominated by overhanging red mangroves and seawalls.

\section{Field sampling and tagging}

Gill nets were used during random and directed sampling for smalltooth sawfish, and sampling trips were conducted during the day in all months be- tween February and September 2014 as part of ongoing research on this species (Poulakis et al. 2011, 2013, 2016). During random sampling, sites were selected from within $1 \times 1$ cartographic grids (1 square nautical mile) that contained water depths up to $3 \mathrm{~m}$ within the study area (see Scharer et al. 2017 for details). Briefly, 2 random trips per month were conducted in northern Charlotte Harbor (8 sites per

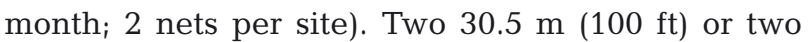

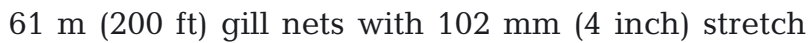
monofilament mesh were set perpendicular to shore about $100 \mathrm{~m}$ apart. In general, the $61 \mathrm{~m}$ nets were used unless we were sampling a confined space (e.g. a small creek or canal). Directed sampling targeted known nursery hotspots, and sites were often selected using recent encounter reports from the public. Gear for directed sampling was either two $45 \mathrm{~m}$ (150 ft) gill nets or one $183 \mathrm{~m}$ (600 ft) gill net, both with $152 \mathrm{~mm}$ 
(6 in) stretch monofilament mesh to minimize bycatch. The $45 \mathrm{~m}$ nets were set perpendicular to shore about $100 \mathrm{~m}$ apart, and the $183 \mathrm{~m}$ net began perpendicular to shore but was usually curved so it eventually became oriented parallel to shore. All gill nets were soaked for $1 \mathrm{~h}$ and checked after $30 \mathrm{~min}$ or whenever fishes of any species were caught (e.g. when splashing was observed).

Captured smalltooth sawfish were tagged externally with a rototag (Dalton ID Systems) equipped with a coded $69 \mathrm{kHz}$ Amirix/Vemco V9 acoustic tag (tag family: V9-2H; $29 \mathrm{~mm}$ long; weight in water = $2.9 \mathrm{~g}$ ), following the methods of Poulakis et al. (2013). In the laboratory, a cable tie covered with epoxy gel was used to attach acoustic transmitters to the flat half of a rototag. When a sawfish was caught, we used a leather punch to make a hole for the projecting half of the rototag so the halves could be joined and attached to the anterior margin of the second dorsal fin (Poulakis et al. 2013, 2016). To minimize potential signal collisions, these tags were programmed to emit a unique acoustic sequence on a random delay once every 80 to $160 \mathrm{~s}$ and had an estimated battery life of $\sim 12 \mathrm{mo}$. To aid active tracking, a few individuals were tagged with an additional acoustic tag on a different frequency $(60,63,75$, or $84 \mathrm{kHz}$ Amirix/Vemco V9 tags) that emitted a signal every $5 \mathrm{~s}$ and had a battery life of $\sim 2$ mo.

\section{Acoustic monitoring and data analysis}

A total of 35 single-frequency omnidirectional VR2W Amirix/Vemco acoustic receivers were moored throughout northern Charlotte Harbor, including the Peace River, to passively monitor acoustically tagged smalltooth sawfish (Fig. 1). Previous smalltooth sawfish captures (daytime sampling; Poulakis et al. 2011, Scharer et al. 2017) occurred along the northern shoreline of the Peace River; although sampling was conducted along the southern shoreline, no sawfish were captured there. For the present study, 5 of the 35 receivers were added to the southern shoreline of the Peace River in 2014 to provide coverage in the vicinity of a planned oyster restoration project. When a signal from an acoustic tag was detected $(800 \mathrm{~m}$ maximum detection range, mean $=450 \mathrm{~m}$; Collins et al. 2008), the receivers logged the date, time, and tag number. Data from the receivers were downloaded regularly, at which point any biofouling on the receivers was removed.

For comparison to previous research (Scharer et al. 2012, Poulakis et al. 2013) and to determine ontoge- netic changes in habitat use, smalltooth sawfish were divided into the following 2 age classes: $<1500 \mathrm{~mm}$ stretch total length (STL), representing $<1$-yr-old fish; and those between 1504 and $1881 \mathrm{~mm}$ STL, representing $\geq 1$-yr-old fish ( 1 to $3 \mathrm{yr}$ old).

Spatial use of the Peace River by sawfish was determined by comparing detections on the northern and southern shorelines. The northern shoreline of the Peace River is a known nursery hotspot for juvenile smalltooth sawfish; that is, research captures and reports of sightings by the public are far more numerous than elsewhere in the upper estuary (Poulakis et al. 2011). The southern shoreline of the Peace River was largely unmonitored prior to this study. To determine whether the 5 new receivers on the southern shoreline detected smalltooth sawfish, an abacus plot of detections using raw data was generated. A chisquare test was used to examine any diel differences in the number of detections at these receivers (day $=$ 09:00 to $16: 59 h_{\text {; night }}=21: 00$ to $05: 59 h_{\text {; }}$ Poulakis et al. 2013). Crepuscular periods were omitted from diel comparisons following previous research (Poulakis et al. 2013). The chi-square test was based on a 5 (number of receivers) $\times 2$ (day vs. night) contingency table. Diel differences in the number of detections (i.e. as determined in the chi-square test) can occur because of changes in detection efficiency between day and night due to changes in the acoustic environment (Simpfendorfer et al. 2008). Also, it is possible that an individual acoustic transmitter could overly influence the chi-square test if it stayed next to a receiver for an extended period of time. To minimize issues related to detection efficiency, we used comprehensive statistical models (that included transmitter number as a random effect) and active tracking (to verify sawfish location estimates) to determine if diel movements occurred.

Generalized linear mixed models with binomial distribution and logit link function were used to estimate the probabilities of detecting $<1$-yr-old and $\geq 1$-yr-old sawfish on receivers associated with either the northern or southern shorelines (glmer function, lme4 R package) (Bates et al. 2015). First, the raw data were reduced by taking the first detection each hour, per receiver, for each smalltooth sawfish using Statistical Analysis Software, version 9.4. Individuals detected by either the north or south receivers were a function of the categorical variable day or night. We fitted mixed-effect random intercept models in the form of South $(0,1) \sim$ Time of day + (1/Transmitter) and North $(0,1) \sim$ Time of day $+(1$ /Transmitter $)$, meaning that only the intercept term in the model was allowed to vary between fish. Transmitter number was mod- 
eled as a random effect to account for multiple detections of any given individual. The response variable was binary, either a 0 if the fish was not present in the modeled location, or a 1 if the fish was present in the modeled location. The models were run separately by age class. The model output provided estimates of the probability of detecting the 2 age classes of smalltooth sawfish along the northern and southern shorelines during both day and night.

To visualize diel habitat use by smalltooth sawfish in the Peace River, contour maps, based on the same data used in the statistical models above (i.e. reduced detection data from acoustic receivers), were created using Surfer, version 13. The contour procedure interpolates the detections across the receiver array. High-use areas are shown as warmer colors (i.e. red and orange). Contour maps were created separately for day and night for the 2 juvenile age classes described above (i.e. $<1 \mathrm{yr}$ old and $\geq 1 \mathrm{yr}$ old).

Acoustic monitoring data were also plotted on short timescales (1 wk) to allow visualization of diel movements of individual sawfish. Previous research using acoustic telemetry assigned river kilometer $(\mathrm{rkm})$ values based on the distance of each receiver from the river mouth, which was assigned rkm 0 (Poulakis et al. 2013, 2016, Scharer et al. 2017). A mean position algorithm was used to estimate the location of sawfish along a 2-dimensional axis in the river. The mean position for a particular time period, $1 \mathrm{~h}$ in this study, was:

$$
\bar{X}_{\mathrm{km}}=\frac{\sum_{i} w_{i} X_{i}}{\sum_{i} w_{i}}
$$

where $x_{i}$ is the distance from station $i$ to the river mouth and $w_{i}$ is the number of valid detections received at each station. Close inspection of these individual movement plots is useful for revealing diel patterns at smaller spatial scales that may be missed in the contour maps that combine data for all individuals at broader spatial scales.

\section{Active tracking and data analysis}

Traditionally, active tracking has involved following tagged individuals over extended periods of time, ideally $24 \mathrm{~h}$, to determine the movements of those individuals (Simpfendorfer et al. 2010, Hollensead et al. 2016). In this study, however, we had 23 smalltooth sawfish tagged in a relatively small area and decided that the most efficient data collection method for our research questions (e.g. distance from
Table 1. Summary of shoreline and bottom habitats at each active tracking site depicted in Fig. 1

\begin{tabular}{|lll|}
\hline Site & Shoreline habitat & Bottom habitat \\
\hline 1 & Beach/concrete dock & Sand/mud/oyster \\
2 & Beach/concrete dock & Sand/mud/oyster \\
3 & Oyster/riprap/seawall & Sand/mud \\
4 & Spartina spp./red mangrove/beach & Sand/mud \\
5 & Seawall & Sand/mud \\
6 & Seawall & Mud \\
7 & Red mangrove/Juncus spp. & Mud/sand/oyster \\
8 & Red mangrove/Juncus spp. & Mud \\
\hline
\end{tabular}

shore, habitat associations) would be to track individuals one at a time until we could estimate a position and determine what habitat(s) it was using, and then move on to acquire data on as many tagged individuals as possible. During the day, tagged smalltooth sawfish were tracked using a directional hydrophone coupled to an Amirix/Vemco VR100 acoustic receiver from a kayak in the documented nursery hotspot area on the northern shoreline of the Peace River (Poulakis et al. 2011). Due to logistics (e.g. time needed to locate sawfish), the sampling area was divided into 8 sites based on shoreline habitat and bottom type (Fig. 1, Table 1). All sites were visited on 2 consecutive days each week for 8 consecutive weeks between 4 June and 22 July 2014. Similar to Hollensead et al. (2016), kayaks were used to access shallow waters $(\geq 0.3 \mathrm{~m})$ and narrow tidal creeks while minimizing disturbance of smalltooth sawfish. The hydrophone was oriented in all directions by a researcher in one of two $3.35 \mathrm{~m}$ Trident ocean kayaks. A researcher on a second kayak recorded data (i.e. ID codes, signal strength, direction) verbalized by the researcher operating the hydrophone. Day tracking events were scheduled based on predicted conditions such as wind, tides, and normal wet season afternoon thunderstorms. The first day of tracking started at Site 1 and covered Sites 1 to 6 ; the second day covered Sites 7 and 8 (Fig. 1). A tracking day typically lasted $8 \mathrm{~h}$, from 09:00 to 17:00 h. During each tracking event, all scheduled sites were scanned for the presence of smalltooth sawfish, and the acoustic receiver reported signal strength $(\mathrm{dB})$ of individuals that were detected. Range testing conducted before the study determined that signals $\geq 75 \mathrm{~dB}$ (approximately $6 \mathrm{~m}$ from the tagged fish) resulted in accurate location estimates, so each smalltooth sawfish was assigned a location using this criterion. When an individual was located, site, tag number, signal strength, time, GPS coordinates, water depth, and habitat were recorded. 
To explore diel differences in habitat use by juvenile smalltooth sawfish, active tracking was conducted at night on 5 occasions between 17 June and 18 July 2014. The same protocols used during the day were used at night (21:00 to 02:00 h), with 1 exception: a $6.7 \mathrm{~m}$ boat was used instead of a kayak, which limited night tracking to waters more than $0.7 \mathrm{~m}$ deep. To prevent disturbance to smalltooth sawfish, whenever possible, the current or wind was used to drift while tracking instead of using the motor. Attempts were made to visit each site used for day tracking as well as deeper habitats.

Post hoc tests were used to compare the number of smalltooth sawfish location estimates per tracking event by site and shoreline habitat. Individuals located $>25 \mathrm{~m}$ from the shoreline were not assigned a shoreline habitat. A Mann-Whitney rank sum test was used to compare the average distance (m) of smalltooth sawfish from shore between day and night. The test compared all position estimates $\geq 75 \mathrm{~dB}$ that occurred during the day to those that occurred at night; age classes (i.e. $<1$ yr old and $\geq 1$ yr old) were tested separately.

\section{RESULTS}

\section{Acoustic monitoring}

A total of 23 smalltooth sawfish Pristis pectinata (760 to $1881 \mathrm{~mm} \mathrm{STL;} \mathrm{mean} \mathrm{=}$ $1308 \mathrm{~mm}$ ) were captured along the northern shoreline of the Peace River and were fitted with acoustic tags (Table 2). Both $<1$-yr-old ( $\mathrm{n}=11$ ) and $\geq 1$-yr-old ( $\mathrm{n}=12$ ) smalltooth sawfish were tagged during the study. Of the 23 tagged fish, the female:male ratio was 1:0.5. Of the 35 acoustic receivers placed throughout the study area, 29 detected smalltooth sawfish. Of the 23 tagged smalltooth sawfish, 22 were detected on at least 1 acoustic receiver in the Peace River, 17 were detected on at least 1 of the 5 southern shoreline receivers, and none were detected on the Myakka River area receivers. Tagged sawfish were monitored for 24 to 183 d during the study period (May to September 2014).

Passive acoustic monitoring revealed diel movement patterns in the Peace River. Although all of the smalltooth sawfish were tagged on the northern shoreline during the day, $96 \%$ of the detections on receivers along the southern shoreline were at night (Fig. 2). Results of the generalized linear mixed model implied sawfish movements from the northern shoreline across the river to the southern shoreline for the $\geq 1$-yr-old age class (Fig. 3). For example, the probability of detecting a $\geq 1$-yr-old sawfish in the known nursery hotspot along the northern shoreline during the day $(86.4 \%)$ was greater than along the southern shoreline (13.6\%). At night, however, the probability of a $\geq 1$-yr-old sawfish being detected along the northern shoreline or southern shoreline was about equal (51.7 and 48.3\%, respectively). This movement toward the southern shoreline at night was not apparent for the $<1$-yr-old sawfish. The probability of detecting a $<1$-yr-old sawfish in the known hotspot along the northern shoreline was greater than along the southern shoreline during both the day and night. Contour maps of

Table 2. Summary of smalltooth sawfish Pristis pectinata caught and tagged in the Peace River, Florida, during the study. All individuals except number 22 received uniquely coded $69 \mathrm{kHz}$ acoustic tags. Dates given as mm/dd/yy. STL $=$ stretch total length; $\mathbf{\square}=$ individual was detected during active tracking; $\mathbf{0}=$ individual was detected on at least 1 of the 5 acoustic receivers on the southern shoreline (see Fig. 1). Dashes indicate that an individual was not actively tracked or not heard on the southern shore. Monitoring period refers to the number of days from when the sawfish was tagged to either the last tag detection within the array or the end of the study

\begin{tabular}{|c|c|c|c|c|c|c|}
\hline Sawfish & $\begin{array}{c}\text { Date } \\
\text { tagged }\end{array}$ & $\begin{array}{l}\text { STL } \\
(\mathrm{mm})\end{array}$ & Sex & $\begin{array}{l}\text { Actively } \\
\text { tracked }\end{array}$ & $\begin{array}{l}\text { Southern } \\
\text { shore }\end{array}$ & $\begin{array}{l}\text { Monitoring } \\
\text { period (d) }\end{array}$ \\
\hline 1 & $03 / 27 / 14$ & 760 & F & - & - & 183 \\
\hline 2 & $04 / 14 / 14$ & 761 & $\mathrm{~F}$ & - & - & 42 \\
\hline 3 & $04 / 17 / 14$ & 1504 & M & $\mathbf{\square}$ & 0 & 161 \\
\hline 4 & $05 / 13 / 14$ & 860 & $\mathrm{~F}$ & $\square$ & 0 & 97 \\
\hline 5 & 05/13/14 & 795 & M & $\mathbf{\square}$ & 0 & 136 \\
\hline 6 & $05 / 13 / 14$ & 825 & $\mathrm{~F}$ & $\square$ & - & 29 \\
\hline 7 & $05 / 13 / 14$ & 863 & M & $\square$ & 0 & 90 \\
\hline 8 & 05/13/14 & 805 & $\mathrm{~F}$ & $\mathbf{\square}$ & - & 98 \\
\hline 9 & $05 / 13 / 14$ & 836 & $\mathrm{~F}$ & $\mathbf{\square}$ & 0 & 98 \\
\hline 10 & $05 / 13 / 14$ & 841 & $\mathrm{~F}$ & $\mathbf{\square}$ & 0 & 117 \\
\hline $11^{\mathrm{a}}$ & 06/06/14 & 1575 & F & $\square$ & 0 & 112 \\
\hline $12^{\mathrm{a}}$ & $06 / 06 / 14$ & 1803 & $\mathrm{~F}$ & $\bar{\square}$ & 0 & 112 \\
\hline $13^{a}$ & $06 / 12 / 14$ & 1556 & $\mathrm{~F}$ & $\overline{\mathbf{a}}$ & 0 & 94 \\
\hline $14^{\mathrm{a}}$ & $06 / 12 / 14$ & 1735 & M & $\square$ & $\bullet$ & 106 \\
\hline 15 & $06 / 23 / 14$ & 1754 & $\mathrm{~F}$ & $\square$ & $\bullet$ & 95 \\
\hline 16 & $06 / 23 / 14$ & 1881 & M & $\square$ & 0 & 95 \\
\hline 17 & $06 / 25 / 14$ & 1741 & $\mathrm{~F}$ & $\square$ & 0 & 93 \\
\hline 18 & $06 / 25 / 14$ & 1642 & $\mathrm{~F}$ & $\mathbf{\square}$ & 0 & 96 \\
\hline 19 & $07 / 02 / 14$ & 1410 & M & $\square$ & 0 & 86 \\
\hline 20 & $07 / 02 / 14$ & 1605 & M & $\square$ & 0 & 46 \\
\hline 21 & $07 / 02 / 14$ & 1582 & $\mathrm{~F}$ & $\bar{\square}$ & 0 & 72 \\
\hline 22 & $07 / 02 / 14$ & 1754 & $\mathrm{~F}$ & - & - & - \\
\hline 23 & 07/03/14 & 1839 & $\mathrm{~F}$ & - & - & - \\
\hline 24 & 08/15/14 & 1125 & M & - & - & 24 \\
\hline
\end{tabular}




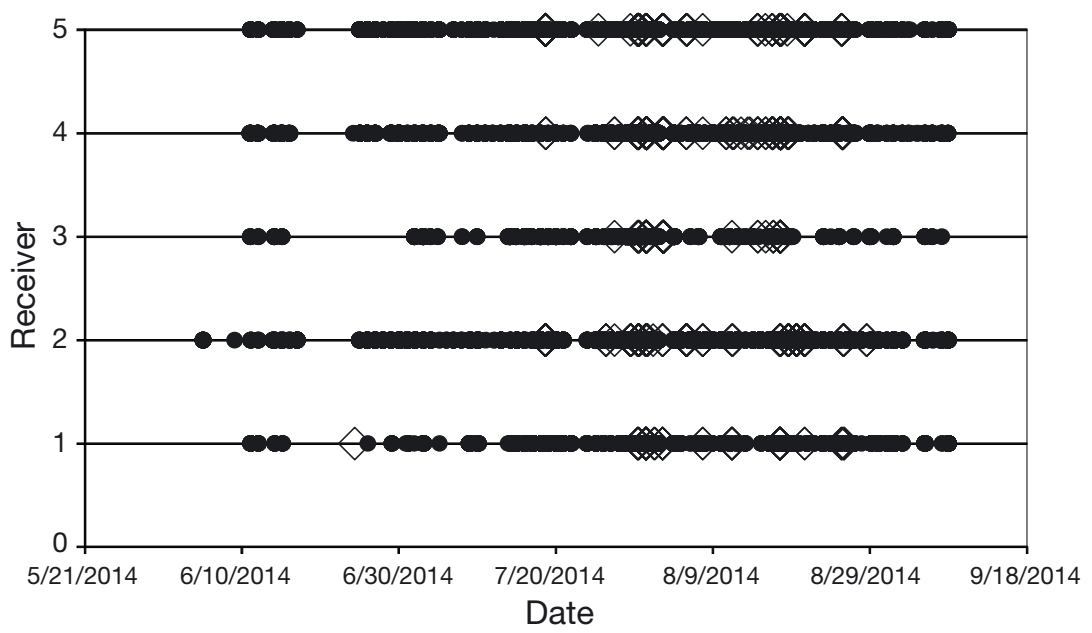

Fig. 2. Monitoring histories of tagged smalltooth sawfish Pristis pectinata on southern shoreline receivers in the Peace River, Florida, May to September 2014 (dates given as mm/dd/yyyy; see Fig. 1 for receiver locations). Raw detections during the day $(09: 00$ to $16: 59 \mathrm{~h}, 4 \%$ of total $\diamond)$ and detections at night $(21: 00$ to $05: 59$ h, $96 \%$ of total; $\bullet$ ) are indicated

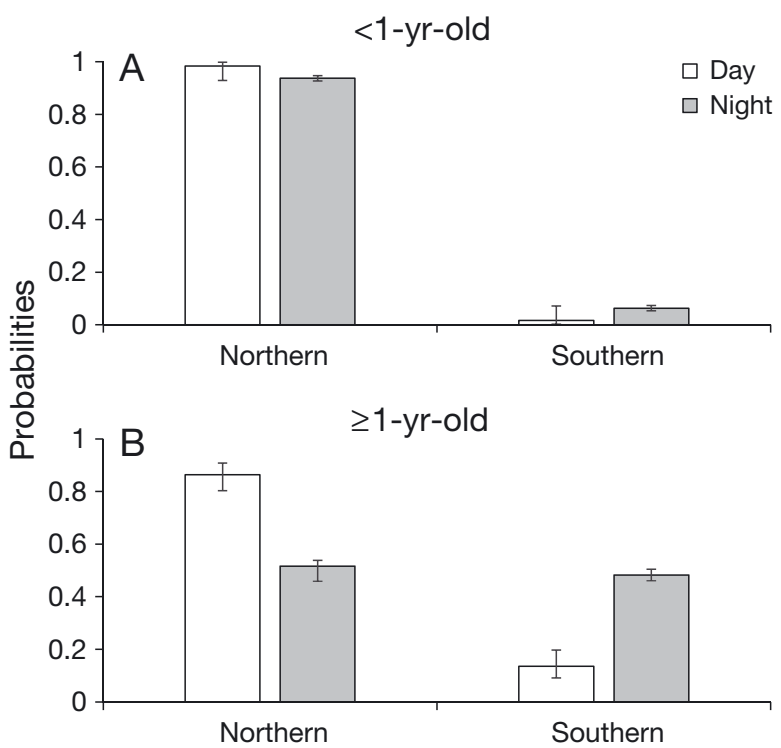

Fig. 3. Probabilities (lower and upper 95\% CI) of smalltooth sawfish Pristis pectinata being detected either at receivers located along the northern or southern shoreline of the Peace River, Florida, during day or night for (A) $<1$-yr-old and (B) $\geq 1$-yr-old age classes

sawfish detection data helped to visualize these diel movement patterns (Fig. 4). Consistent with the generalized linear mixed model, individuals $<1 \mathrm{yr}$ old were associated with the northern shoreline during both day and night (Fig. 4A,B); however, $\geq 1$-yr-old sawfish used the northern shoreline during the day and made excursions down and across the river at night (Fig. 4C,D).
Individual movement tracks of sawfish illustrated typical diel patterns on short timescales (1 wk; Fig. 5). Although large-spatial-scale diel movements of the $<1 \mathrm{yr}$ olds were not apparent from the contour maps that combined data by age class, individual tracks showed that diel movements did occur on a finer spatial scale. Of all <1 yr olds, $82 \%$ exhibited a diel pattern over their 7 to $52 \mathrm{~d}$ monitoring periods for periods up to 17 consecutive days. For example, <1 yr olds typically remained in the protected cove (Site 7) during the day and ventured downriver just outside of the cove $(\sim 2 \mathrm{rkm}$ away, Sites 1 and 2 ) at night (Fig. 5A). Similarly, all $\geq 1$-yr-old sawfish exhibited a diel pattern from 10 to $70 \mathrm{~d}$ during their monitoring periods, including up to 20 consecutive days. For example, a typical $\geq 1$-yr-old individual remained in the protected cove during the day and made further excursions downriver (as far as $7 \mathrm{rkm}$ ) and also toward the southern shoreline at night (Fig. 5B).

\section{Active tracking}

Of the 23 smalltooth sawfish that received an acoustic tag, 19 were detected during active tracking (day and night combined) to examine habitat use along the northern shoreline of the Peace River. Tracking took place over a total of $18 \mathrm{~d}$ during an 8 wk period (day and night combined), and 86 location estimates were established throughout the study area.

Active tracking corroborated the results of the passive monitoring and allowed fine-scale inferences about habitat use in the nursery hotspot. The number of position estimates taken per tracking event during the day was at least 3.7 times greater in a protected, red-mangrove-lined cove (Site 7 ; Fig. 1) than at the other sites (Tukey's post hoc test, p < 0.037; Fig. 6). Of all location estimates that were close to shore $(<25 \mathrm{~m}), 77 \%$ were associated with red mangrove shorelines. Smalltooth sawfish were not located at Sites 1 (oyster-covered concrete docks), 4 (beach, red mangrove, and emergent grasses), or 6 (concrete seawall and red-mangrove-lined canals). At night, the mean distance to shore for smalltooth sawfish (all sawfish combined) was $149 \mathrm{~m}$ greater than during 

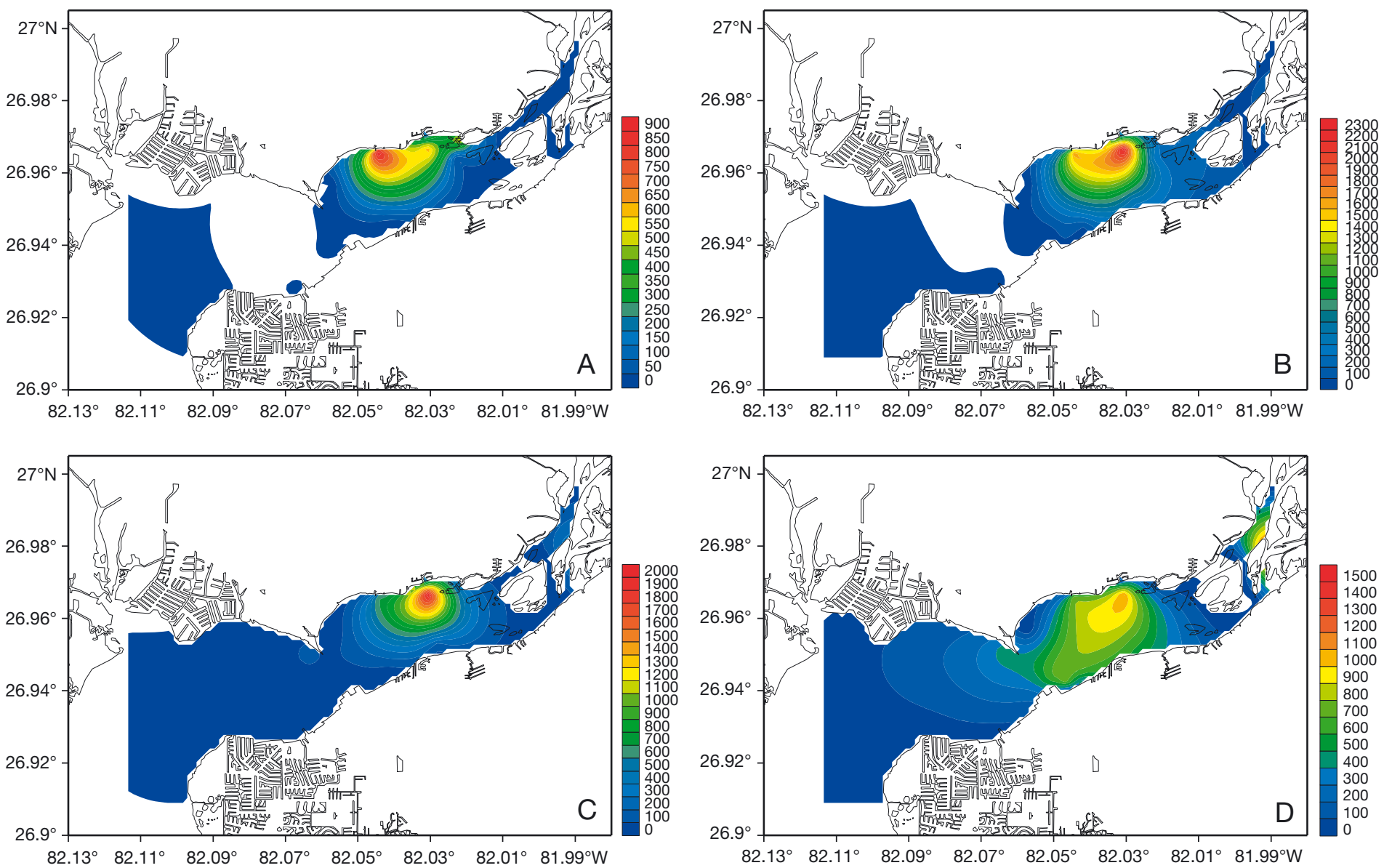

Fig. 4. Diel movement of $<1$-yr-old $(\mathrm{n}=11)$ and $\geq 1$-yr-old $(>1500 \mathrm{~mm} \mathrm{STL} ; \mathrm{n}=12)$ age classes of smalltooth sawfish Pristis pectinata throughout the study period (May to September 2014) in the Peace River, Florida. (A) All <1-yr-old daytime acoustic receiver detections, (B) all <1-yr-old nighttime acoustic receiver detections, (C) all $\geq 1$-yr-old daytime acoustic receiver detections, and (D) all $\geq 1$-yr-old nighttime acoustic receiver detections. Scale bars represent the first detection per hour, per receiver, for each individual (see 'Acoustic monitoring and data analysis' in 'Materials and methods')
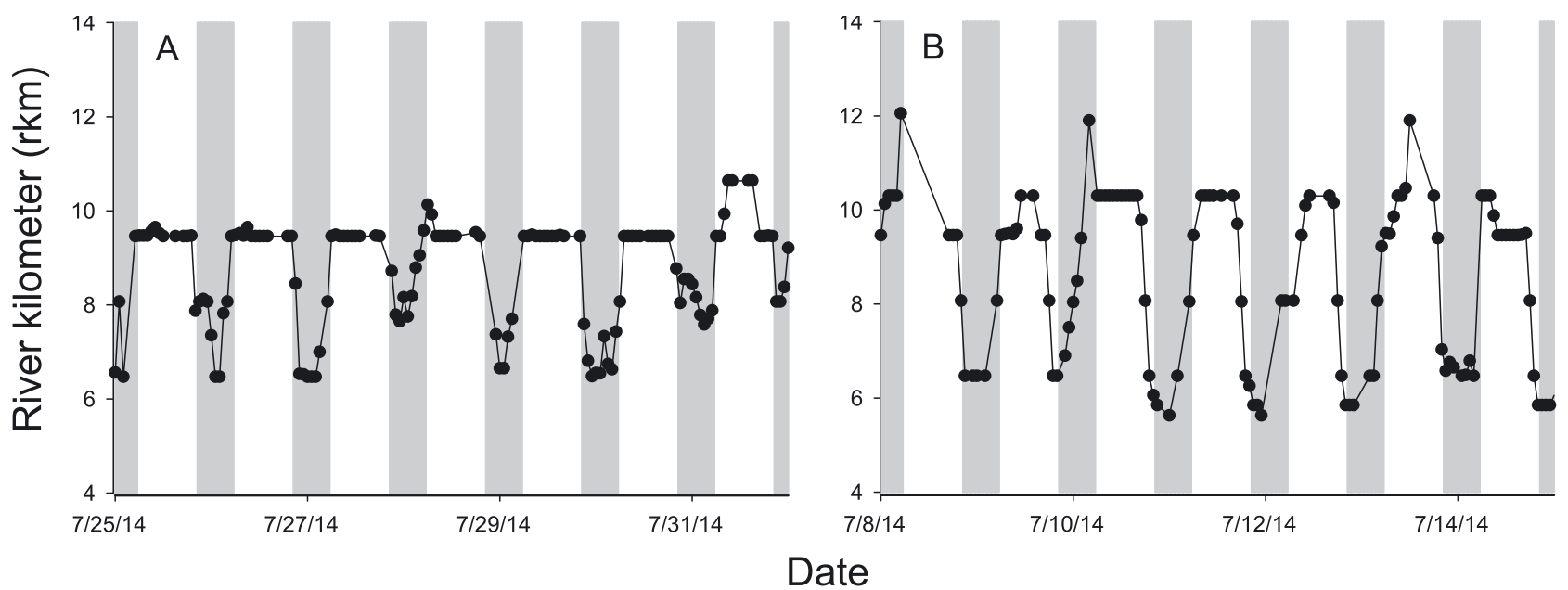

Fig. 5. Examples of diel movement patterns of smalltooth sawfish Pristis pectinata in the Peace River, Florida, by date (mm/dd/yy): (A) <1-yr-old (841 mm STL), (B) $\geq 1$-yr-old (1803 mm STL). River kilometer (rkm) refers to the distance from the river mouth (i.e. from rkm 0). Gray bars indicate night. Acoustic receivers at rkm 9 to 11 were located inside a protected cove (Site 7 in Fig. 1). In general, individuals of both age classes remained in the protected cove during the day and moved downriver and toward the southern shoreline at night between 17:00 and 24:00 $\mathrm{h}$, and returned to the cove between 05:00 and 08:00 $\mathrm{h}$ 


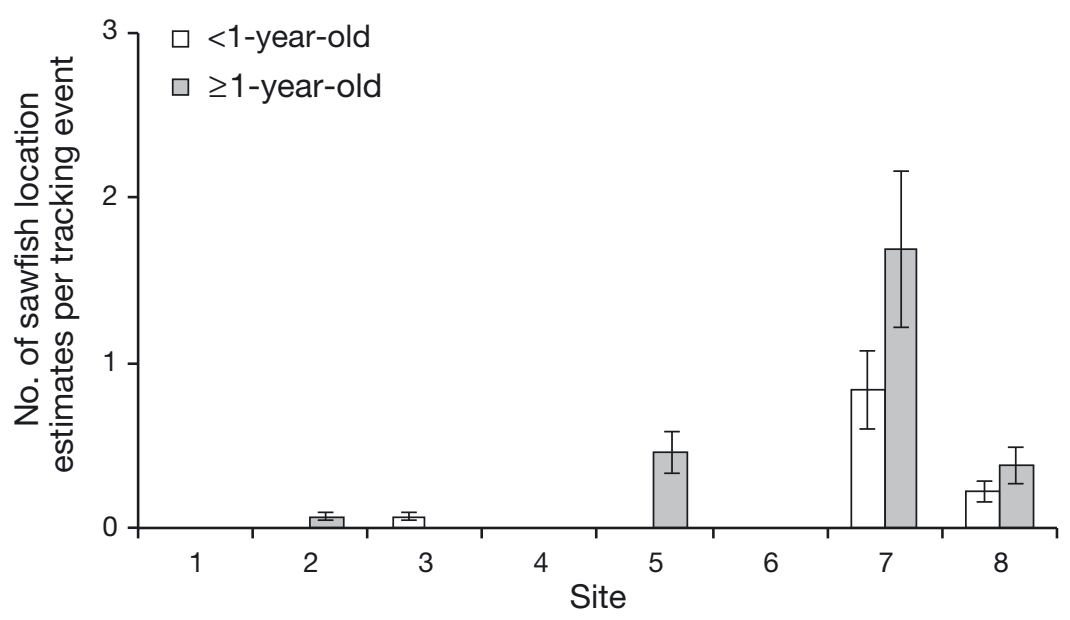

Fig. 6. Mean $( \pm \mathrm{SE})$ number of smalltooth sawfish Pristis pectinata located during all daytime tracking events at Sites 1 to 8 (see Fig. 1 for site locations) along the northern shoreline of the Peace River, Florida, for $<1$-yr-old and $\geq 1$-yr-old ( $>1500 \mathrm{~mm}$ STL) age classes during 2014. Pre-study range testing determined that signals $\geq 75 \mathrm{~dB}$ (approximately $6 \mathrm{~m}$ from the tagged fish) resulted in accurate location estimates, so each smalltooth sawfish was located using this criterion

the day (Mann-Whitney rank sum test, $\mathrm{p}<0.001$ ). Distance to shore was analyzed separately for each age class, and results were similar $(<1$ yr old: $172 \mathrm{~m}$ further from shore at night; $\geq 1$ yr old: $140 \mathrm{~m}$ further from shore at night) (Fig. 7).

\section{DISCUSSION}

Documenting diel movements of fishes is dependent on the geomorphology of the study area and the orientation of the acoustic array, and is aided by the use of multiple tracking techniques (Simpfendorfer et al. 2010, Poulakis et al. 2013, Scharer et al. 2017).

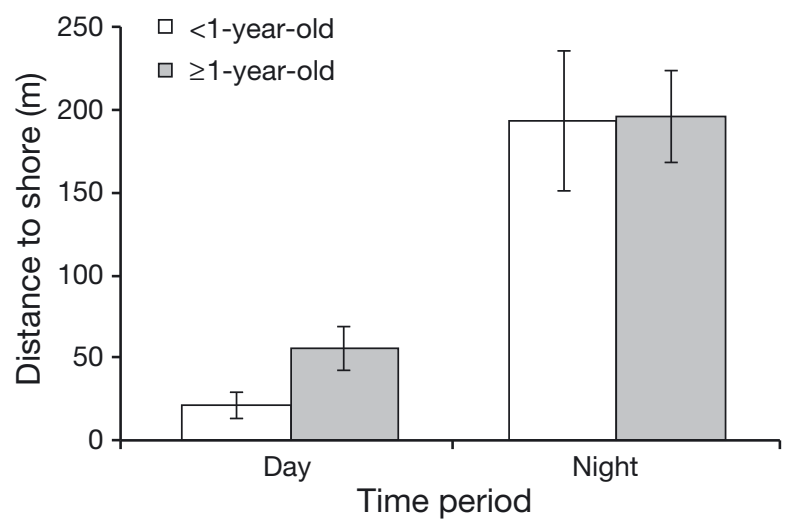

Fig. 7. Mean $( \pm \mathrm{SE})$ distance to shore for smalltooth sawfish Pristis pectinata for $<1$-yr-old and $\geq 1$-yr-old ( $>1500 \mathrm{~mm} \mathrm{STL)}$ age classes during day and night active tracking events in the Peace River, Florida, during 2014
Although Hollensead et al. (2016) tested for diel differences in movement rates of smalltooth sawfish Pristis pectinata in their Ten Thousand Islands study, none were found. Differences in habitat geomorphology between the Ten Thousand Islands and the large rivers of the Charlotte Harbor estuarine system may explain the difference between these findings. In the Ten Thousand Islands, some smalltooth sawfish nursery hotspots are composed of small, protected embayments and narrow tributaries. Any movement away from the shoreline at night is difficult to detect with moored receivers, or during active tracking, because the habitat is so confined. Conversely, in the rivers of Charlotte Harbor, the nursery hotspots lie within broad areas of the rivers. In the Peace River, smalltooth sawfish moved away from the northern shoreline and used larger portions of the river at night. The 5 acoustic receivers on the south side of the river regularly detected tagged smalltooth sawfish, and most (96\%) of the detections there occurred at night. With passive acoustic methods alone, we might have concluded that the greater number of nighttime detections resulted from diel changes in detection efficiency, because the detection range of receivers could vary between day and night as a result of changes in ambient noise (e.g. from boats; Simpfendorfer et al. 2008). However, active tracking confirmed the movement of smalltooth sawfish away from the northern shoreline at night. Likewise, if active tracking had been used alone, with more than 20 individuals along a shoreline on a given night, we might have missed smalltooth sawfish that had moved far from shore. The use of multiple techniques to explore nursery hotspots and diel patterns of activity revealed findings that would not have been discovered using a single technique.

The driver for the diel movements of smalltooth sawfish may be related to 'refuging', a behavior in which individuals stay in a central location during the day, preserving their energy, then leave the area at night to feed (Hamilton \& Watt 1970). This behavior has been documented in several elasmobranch species. For example, in the Gulf of California, scalloped hammerheads Sphyrna lewini were observed along a ridge during the day, which they left at night when foraging (Klimley \& Nelson 1984). In Australia's 
Fitzroy River, the largetooth sawfish Pristis pristis was more active at night than during the day (Whitty et al. 2017, this Theme Section). These authors concluded that juvenile largetooth sawfish exhibited refuging behavior, being associated with large woody debris in deeper water during the day and foraging at night in shallower water to take advantage of an increase in prey there and better foraging efficiency due to the depth difference. During night tracking of smalltooth sawfish in the Ten Thousand Islands, Hollensead et al. (2016) observed schools of baitfish on sand bars and inferred that feeding occurred at night away from shore. Poulakis et al. (2016) suggested the periodic movement of smalltooth sawfish into the main stem of the Caloosahatchee River at night was for foraging, while during the day they avoided predation by staying in non-main-stem areas of the river. In the present study, it is unknown whether smalltooth sawfish moved away from the northern shoreline out to the center of the river, within range of receivers on the southern shore, or regularly crossed the entire river to the southern shoreline. Greater resolution of sawfish position estimates within the Peace River array $(\sim 1$ to $3 \mathrm{~m})$ using triangulation algorithms is underway. The attachment of acceleration data loggers to individual sawfish (e.g. Whitney et al. 2012) aims to determine differences in movement rates and possibly feeding behavior between day and night (Gleiss et al. 2017). The first step in this research design was to define the boundaries of the smalltooth sawfish nursery hotspot in the Peace River to know exactly where to deploy these expensive technologies.

Acoustic telemetry provided information on habitat use of 2 age classes of juvenile smalltooth sawfish in the Peace River. During the day, all individuals remained closer to shoreline vegetation along the northern shore of the river in a protected cove. Although a variety of habitat types were available along the northern shoreline (e.g. seawall, riprap, emergent vegetation), smalltooth sawfish resided in a protected, red-mangrove-lined embayment (i.e. protected cove). These results were supported by both passive acoustic monitoring and active tracking (see Figs. 4, 5 \& 6; Site 7 had the greatest number of position estimates). The conditions within this embayment are consistent with other smalltooth sawfish nurseries, including the hotspots within them (Seitz \& Poulakis 2002, Poulakis \& Seitz 2004, Wiley \& Simpfendorfer 2010, Poulakis et al. 2011, 2016, Hollensead et al. 2016). It is possible, however, that the location of highest smalltooth sawfish use can shift slightly $(\sim 2 \mathrm{rkm})$ from year to year with reasons unknown. In some years, the highest capture rate of juvenile smalltooth sawfish has been observed just outside the protected cove within Sites 1 and 2 (daytime sampling; Poulakis et al. 2011), whereas in this study, Sites 7 and 8 were most heavily used. Generalized linear mixed models and contour maps based on acoustic monitoring indicated movements further from shore than active tracking showed and demonstrated that the $\geq 1$-yr-old age class ( $>1500 \mathrm{~mm}$ ) moved more broadly within the nursery hotspot than $<1$ yr olds, similar to the ontogenetic changes Whitty et al. (2009) found in the largetooth sawfish P. pristis. Increasing activity space with size has been reported for the smalltooth sawfish (Simpfendorfer et al. 2011, Poulakis et al. 2013, Hollensead et al. 2016), and a variety of elasmobranchs undertake diel and ontogenetic changes in movement.

The fine-scale habitat information and diel differences in movement determined from the present study are relevant to management of the smalltooth sawfish. The northern shoreline of the Peace River has been consistently identified as the only known nursery hotspot for juvenile smalltooth sawfish in the northern portion of Charlotte Harbor (Poulakis et al. 2011, Scharer et al. 2017). Data from this study, however, suggest that the boundary of the hotspot should be expanded to include the southern shoreline as well (see Fig. 1). Managers should recognize that the Peace and Caloosahatchee rivers contain different numbers of nursery hotspots. This may be attributed to differences in the length of the lower portions of the rivers. The lower Peace River - the broad section between the narrow oligohaline waters upriver of the hotspot and the open estuary - is relatively short ( 10 rkm). In comparison, the lower Caloosahatchee River is 3 times longer and contains at least 4 nursery hotspots (Poulakis et al. 2011, Scharer et al. 2017). Juveniles are known to move between hotspots in the Caloosahatchee River, seasonally with changes in freshwater inflows or sometimes suddenly in response to acute freshwater discharges associated with storm events (Poulakis et al. 2013, 2016). In the Peace River, smalltooth sawfish are more likely to remain in the one hotspot and tolerate lower salinities (Scharer et al. 2017). Although none of the sawfish from this study were detected in the Myakka River, sawfish are known to use this area (Poulakis et al. 2011, Scharer et al. 2017). Areas used often by smalltooth sawfish are sometimes later found to be part of a larger nursery hotspot. Such was the case for an intensive study of hotspots in the Caloosahatchee River; a canal system used by smalltooth sawfish was found to be part of a larger hotspot (Poulakis et al. 2016, Scharer et al. 2017). 
Identifying the boundaries of a sawfish nursery hotspot within federally designated critical habitat is an important step for considering any management approaches that include layers of protection across space. The Peace River nursery hotspot represents the only known high-use area for the smalltooth sawfish within the northern Charlotte Harbor estuary, and this is the northernmost hotspot in the current range of the species. Site fidelity in this river appears high, given the propensity for individuals to remain in the hotspot even though changes related to freshwater inflow can be as dramatic as those in the nearby Caloosahatchee River (Scharer et al. 2017), which receives large discharges from Lake Okeechobee. In addition, new genetic information indicates that the species exhibits philopatry; adult females return to the Peace River to give birth on a biennial cycle (Feldheim et al. 2017, this Theme Section). Thus, this known smalltooth sawfish nursery habitat must receive the highest level of protection - perhaps higher than elsewhere in the federally designated juvenile critical habitat in the Charlotte Harbor Estuary Unit (Norton et al. 2012). We now have a good understanding of the boundaries of the Peace River nursery hotspot. Similar studies of other known nursery hotspots throughout the smalltooth sawfish range would also be helpful in determining the areas the sawfish use during both day and night to be able to protect those areas. This information could be used to inform managers who review development activities, management plans, and restoration opportunities that affect the smalltooth sawfish and its habitats.

Acknowledgements. The work was supported by funding from The Nature Conservancy (grant award number 01122014-001) and the US Department of Commerce (DOC), National Oceanic and Atmospheric Administration's (NOAA) National Marine Fisheries Service through section 6 (Cooperation with the States) of the US Endangered Species Act under the following grant award to the Florida Fish and Wildlife Conservation Commission (FWC): from the DOC, NOAA - NA13NMF4720047. We thank the staff at the FWC's Charlotte Harbor Field Laboratory for assistance with the capture and tagging of smalltooth sawfish. Bland Crowder, Geoff Huston, Courtney Saari, and 4 anonymous reviewers improved earlier versions of the manuscript. We also thank Dave Blewett for helping with the statistical analyses. This research was conducted under Endangered Species Permit number 15802 issued by the National Marine Fisheries Service (NOAA Fisheries). This work was presented as part of the symposium 'Biology and Ecology of Sawfishes' at the 2016 annual meeting of the American Elasmobranch Society, which was supported by funding from the Save Our Seas Foundation, Disney Conservation Fund, and the American Elasmobranch Society.

\section{LITERATURE CITED}

Bates D, Maechler M, Bolker B, Walker S (2015) Fitting linear mixed-effects models using lme4. J Stat Softw 67:1-48

Carlson J, Wiley T, Smith K (2013) Pristis pectinata. The IUCN Red List of Threatened Species 2013: e.T18175 A43398238. http://dx.doi.org/10.2305/IUCN.UK.2013-1. RLTS.T18175A43398238.en (accessed 17 April 2017)

C Cartamil DP, Vaudo JJ, Lowe CG, Wetherbee BM, Holland KN (2003) Diel movement patterns of the Hawaiian stingray, Dasyatis lata: implications for ecological interactions between sympatric elasmobranch species. Mar Biol 142:841-847

Collins AB, Heupel MR, Simpfendorfer CA (2008) Spatial distribution and long-term movement patterns of cownose rays Rhinoptera bonasus within an estuarine river. Estuaries Coasts 31:1174-1183

Dulvy NK, Fowler SL, Musick JA, Cavanagh RD and others (2014) Extinction risk and conservation of the world's sharks and rays. eLife 3:e00590

*Dulvy NK, Davidson LNK, Kyne PM, Simpfendorfer CA, Harrison LR, Carlson JK, Fordham SV (2016) Ghosts of the coast: global extinction risk and conservation of sawfishes. Aquat Conserv 26:134-153

Feldheim KA, Fields AT, Chapman DD, Scharer RM, Poulakis GR (2017) Insights into reproduction and behavior of the smalltooth sawfish Pristis pectinata. Endang Species Res, doi:10.3354/esr00868

FWC (Florida Fish and Wildlife Conservation Commission) (1999) Protected species: sawfishes, basking shark, white shark, sand tiger shark, bigeye sand tiger shark, manta ray and spotted eagle ray; prohibition of harvest, landing, or sale. Chapter 68B-44.008. Florida Administrative Code Rule

*Gleiss AC, Morgan DL, Whitty JM, Keleher JJ, Fossette S, Hays GC (2017) Are vertical migrations driven by circadian behavior? Decoupling of activity and depth use in a large riverine elasmobranch, the freshwater sawfish (Pristis pristis). Hydrobiologia 787:181-191

* Hamilton WJ, Watt KE (1970) Refuging. Annu Rev Ecol Syst $1: 263-286$

Kolland KN, Wetherbee BM, Peterson JD, Lowe CG (1993) Movements and distribution of hammerhead shark pups on their natal grounds. Copeia 1993:495-502

*Hollensead LD, Grubbs RD, Carlson JK, Bethea DM (2016) Analysis of fine-scale daily movement patterns of juvenile Pristis pectinata within a nursery habitat. Aquat Conserv 26:492-505

Klimley AP, Nelson DR (1984) Diel movement patterns of the scalloped hammerhead shark (Sphyrna lewini) in relation to El Bajo Espiritu Santo: a refuging central-position social system. Behav Ecol Sociobiol 15:45-54

Kyne PM, Carlson J, Smith K (2013) Pristis pristis. The IUCN Red List of Threatened Species: e.T18584848A18620395. http://dx.doi.org/10.2305/IUCN.UK.2013-1.RLTS.T18584 848A18620395.en (accessed 17 April 2017)

*Matern SA, Cech JJ Jr., Hopkins TE (2000) Diel movements of bat rays, Myliobatis californica, in Tomales Bay, California: evidence for behavioral thermoregulation. Environ Biol Fishes 58:173-182

NMFS (National Marine Fisheries Service) (2003) Endangered and threatened species; final endangered status for a distinct population segment of smalltooth sawfish (Pristis pectinata) in the United States. Fed Regist 68: 15674-15680 
NMFS (National Marine Fisheries Service) (2009) Endangered and threatened species; critical habitat for the endangered distinct population segment of smalltooth sawfish. Fed Regist 74:45353-45378

Norton SL, Wiley TR, Carlson JK, Frick AL, Poulakis GR, Simpfendorfer CA (2012) Designating critical habitat for juvenile endangered smalltooth sawfish in the United States. Mar Coast Fish 4:473-480

Poulakis GR, Seitz JC (2004) Recent occurrence of the smalltooth sawfish, Pristis pectinata (Elasmobranchiomorphi: Pristidae), in Florida Bay and the Florida Keys, with comments on sawfish ecology. Fla Sci 67:27-35

Poulakis GR, Blewett DA, Mitchell ME (2003) The effects of season and proximity to fringing mangroves on seagrassassociated fish communities in Charlotte Harbor, Florida. Gulf Mex Sci 2:171-184

Poulakis GR, Stevens PW, Timmers AA, Wiley TR, Simpfendorfer CA (2011) Abiotic affinities and spatiotemporal distribution of the endangered smalltooth sawfish, Pristis pectinata, in a south-western Florida nursery. Mar Freshw Res 62:1165-1177

*Poulakis GR, Stevens PW, Timmers AA, Stafford CJ, Simpfendorfer CA (2013) Movements of juvenile endangered smalltooth sawfish, Pristis pectinata, in an estuarine river system: use of non-main-stem river habitats and lagged responses to freshwater inflow-related changes. Environ Biol Fishes 96:763-778

Poulakis GR, Stevens PW, Timmers AA, Stafford CJ and others (2016) Long-term site fidelity of endangered smalltooth sawfish (Pristis pectinata) from different mothers. Fish Bull 114:461-475

Scharer RM, Patterson WF III, Carlson JK, Poulakis GR (2012) Age and growth of endangered smalltooth sawfish (Pristis pectinata) verified with LA-ICP-MS analysis of vertebrae. PLOS ONE 7:e47850

Scharer RM, Stevens PW, Shea CP, Poulakis GR (2017) All nurseries are not created equal: large-scale habitat use patterns in two smalltooth sawfish nurseries. Endang Species Res, doi:10.3354/esr00871

Editorial responsibility: Eduardo Martins, Vancouver, British Columbia, Canada
Seitz JC, Poulakis GR (2002) Recent occurrence of sawfishes (Elasmobrachimorphi: Pristidae) along the southwest coast of Florida (USA). Fla Sci 65:256-266

Simpfendorfer C (2013) Pristis zijsron. The IUCN Red List of Threatened Species: e.T39393A18620401. http://dx.doi. org/10.2305/IUCN.UK.2013-1.RLTS.T39393A18620401.en (accessed 17 April 2017)

Simpfendorfer CA, Heupel MR, Collins AB (2008) Variation in the performance of acoustic receivers and its implication for positioning algorithms in a riverine setting. Can J Fish Aquat Sci 65:482-492

* Simpfendorfer CA, Wiley TR, Yeiser BV (2010) Improving conservation planning for an endangered sawfish using data from acoustic telemetry. Biol Conserv 143: 1460-1469

Simpfendorfer CA, Yeiser BG, Wiley TR, Poulakis GR, Stevens PW, Heupel MR (2011) Environmental influences on the spatial ecology of juvenile smalltooth sawfish (Pristis pectinata): results from acoustic monitoring. PLOS ONE 6:e16918

Whitney NM, Papastamatiou YP, Gleiss AC (2012) Integrative multisensory tagging: emerging techniques to link elasmobranch behavior, physiology, and ecology. In: Carrier JC, Musick JA, Heithaus MR (eds) Biology of sharks and their relatives, 2nd edn. CRC Press, Boca Raton, FL, p 265-290

*Whitty JM, Morgan DL, Peverell SC, Thorburn DC, Beatty ST (2009) Ontogenetic depth partitioning by juvenile freshwater sawfish (Pristis microdon: Pristidae) in a riverine environment. Mar Freshw Res 60:306-316

Whitty JM, Keleher J, Ebner BC, Gleiss AC, Simpfendorfer CA, Morgan DL (2017) Habitat use of a Critically Endangered elasmobranch, the largetooth sawfish Pristis pristis, in an intermittently flowing riverine nursery. Endang Species Res 34:211-227

Wiley TR, Simpfendorfer CA (2010) Using public encounter data to direct recovery efforts for the endangered smalltooth sawfish Pristis pectinata. Endang Species Res 12: 179-191

Submitted: October 13, 2016; Accepted: July 6, 2017 Proofs received from author(s): October 2, 2017 